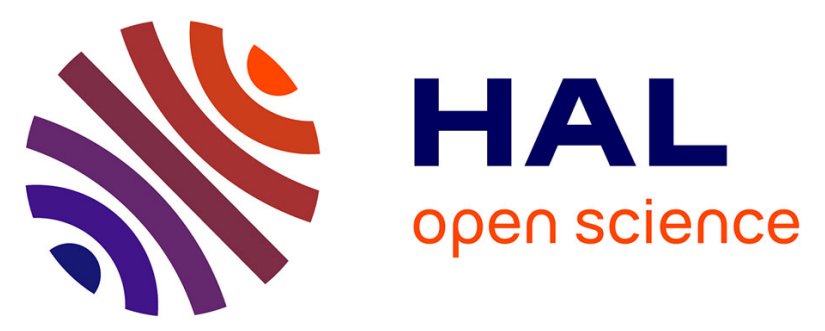

\title{
A Flexible Biopolymer based UHF RFID-Sensor for food quality monitoring
}

Benjamin Saggin, Yassin Belaizi, Arnaud Vena, Brice Sorli, Valérie Guillard, Isabelle Dedieu

\section{- To cite this version:}

Benjamin Saggin, Yassin Belaizi, Arnaud Vena, Brice Sorli, Valérie Guillard, et al.. A Flexible Biopolymer based UHF RFID-Sensor for food quality monitoring. 2019 IEEE International Conference on RFID Technology and Applications (RFID-TA), Sep 2019, Pisa, Italy. pp.484-487, 10.1109/RFIDTA.2019.8892248 . hal-02136870

\section{HAL Id: hal-02136870 https://hal.science/hal-02136870}

Submitted on 19 Dec 2019

HAL is a multi-disciplinary open access archive for the deposit and dissemination of scientific research documents, whether they are published or not. The documents may come from teaching and research institutions in France or abroad, or from public or private research centers.
L'archive ouverte pluridisciplinaire HAL, est destinée au dépôt et à la diffusion de documents scientifiques de niveau recherche, publiés ou non, émanant des établissements d'enseignement et de recherche français ou étrangers, des laboratoires publics ou privés. 


\section{A Flexible Biopolymer based UHF RFID-Sensor}

\section{for food quality monitoring}

\author{
Benjamin SAGGIN \\ Institute of Electronics and Systems \\ University of Montpellier \\ Montpellier. France \\ benjamin.saggin@umontpellier.fr
}

Brice SORLI

Institute of Electronics and Systems

University of Montpellier

Montpellier. France

brice.sorli@umontpellier.fr

\author{
Yassin BELAIZI \\ Institute of Electronics and Systems \\ University of Montpellier \\ Montpellier. France \\ yassin.belaizi@umontpellier.fr \\ Valerie GUILLARD \\ Agropolymer Engineering and \\ Emerging Technologies \\ University of Montpellier \\ Montpellier. France \\ valerie.guillard@umontpellier.fr
}

\author{
Arnaud VENA \\ Institute of Electronics and Systems \\ University of Montpellier \\ Montpellier. France \\ (D) arnaud.vena@umontpellier.fr \\ Isabelle DEDIEU \\ Agropolymer Engineering and \\ Emerging Technologies \\ University of Montpellier \\ Montpellier. France \\ isabelle.dedieu@umontpellier.fr
}

\begin{abstract}
This paper introduces a flexible UHF RFID sensor to detect food quality. This sensor is based on an interdigitated capacity included in a RFID antenna on which is deposited a layer of vegetal biopolymer. Thus, depending on the food spoilage, electromagnetic coupling between the capacity and the biopolymer is used to modulate adaptation coefficient between chip and antenna of the RFID tag. This study is validated by experimental measurements of RFID-sensor exposed to real food gas environment in the process of degradation.
\end{abstract}

Keywords-RFID, sensor, UHF, EPC standard, agri-food, biopolymer, wheat gluten, food quality, food spoilage

\section{INTRODUCTION}

Radio Frequency Identification (RFID) technology is increasingly prevalent in traceability and commodity management applications. This technology has the advantage of tracking stocks faster by allowing to read RFID tags affixed to products, few meters away and without direct visibility. In recent years, this technology has attracted growing interest in pharmaceutical and agri-food industry [1], including the fact that it becomes possible to add sensor information to identification [2]. Sensing property is done according to two techniques: first requires the use of an internal or external digital sensor to the RFID chip; second method, less costly and which is the subject of this paper, is based on antenna surface functionalization by a sensitive material. In this case, the sensor information is "analog" and correlated with impedance tweak between antenna and chip. Impedance adaptation is due to the electrical complex permittivity of sensitive material that evolves following influence of physical parameter to be measured.

In this article, an RFID-sensor, studied beforehand [3], is presented and suited to agri-food field in order to produce a food packaging called "smart" as illustrated in Fig. 1. The

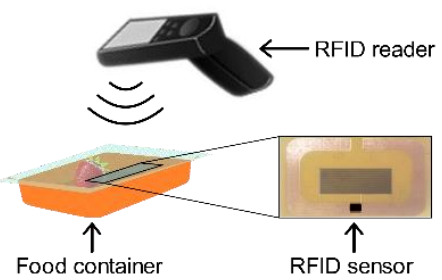

Fig. 1 RFID-sensor concept objective is to measure evolution of food spoilage by using a UHF RFID-sensor in complex environment composed of different gases.

\section{RFID-SENSOR GEOMETRY AND DETECTION PRINCIPLE}

As noted above, a low-cost RFID-sensor is presented here, and the adaptation coefficient $\gamma(\psi)$, between the antenna and a conventional RFID chip, contains the sensing parameter, the physical parameter, $\psi$. On RFID reader side, extracting the sensor information is to track evolution of transmitted power required to activate the tag, $p^{T X}$ turn-on and/or the reflected power by the tag, $p^{R X}$ turn-on. To extract the sensor value, it is a matter of finding a relationship between physical parameter and activation power. The geometry shown in Fig. 2 is based on a folded dipole. To maximize the variation of $\gamma(\psi)$, an inter-digited capacity is connected in parallel to the chip [4].

RFID chip used in this study is sold by Magicstrap, based on a chip NXP G2XM $\left(Z_{I C}=20\right.$-j200 to $\left.867 \mathrm{MHz}\right)$. The sensitive area of the RFID-s ensor is represented by the blue-green zone in Fig. 2. Intended agri-food application concerns the realization of a device for monitoring degradation stage of food present in its packaging. This measurand takes very different forms depending on the nature of food [5]: increase of carbon dioxide $\left(\mathrm{CO}_{2}\right)$ concentration, release of ethanol (...) during fermentation, etc... Our choice, concerning the detection material, has been a biological element, thus subjected, also, to degradation: wheat gluten. This plant biopolymer presents a modification of its electrical

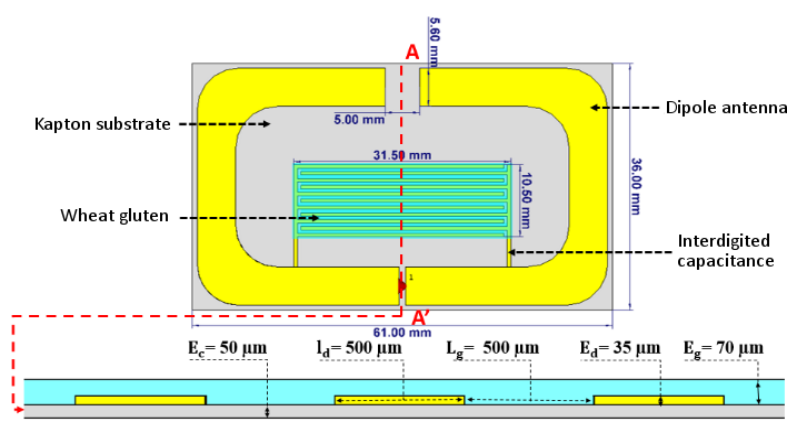

Yellow $=$ copper, Grey $=$ polyimide, Blue-green $=$ wheat gluten

Fig. 2 Sensor design

This research was funded by European "Framework Programs for Research and TechnologicalDevelopment"instrument called "Horiz on 2020 " within "GLOP ACK" project and by French "National Agency for Research" within "SPIDLab" project.

XXX-X-XXXX-XXXX-X/XX/\$XX.00 (20XX IEEE 
permittivity properties according to several parameters [1]. Wheat gluten electrical permittivity has been characterized for different environments, to varying humidity and to the presence of different gases [6]-[8]. However, wheat gluten has not been tested in a real, complex environment (presence of various gases) and integrated into food packaging. Therefore, this RFID-sensor will be exposed to an environment, such as hermetic food packaging, where biological degradation is located, and gas concentrations are changed as well. Gas concentrations changes are main sensing targets in this paper.

The RFID-sensor is characterized by an optimal adaptation at around $928 \mathrm{MHz}$ when the sensitive material is completely dry (low humidity) and it has not adsorbed gas, as shown in the Fig. 3. This graph presents simulation result, obtained using CST Microwave Studio software. Moisture variation was simulated from changes in electrical permittivity observed on gluten in previous experiments [9].

Exposure to significant relative humidity, or to various gas concentrations, increases relative electrical permittivity of the sensitive material and thus shifting optimal adaptation of RFID tag to lower frequencies and to lower gains. Of course, standard reader cannot sweep frequencies for 200 $\mathrm{MHz}$, there are constrained to North American (902-928 $\mathrm{MHz}$ ) and European (865.4-867.4 MHz) frequency bands. But, even with these limitations, many options are available. The tracking can be done for a fixed frequency and variation of power $\left(p^{T X}\right.$ turn-on $)$ required to activate the tag is observable as shown in Fig. 5. Use of Analog Identifier (AID) [10], introduced by Gaetano Marrocco, can also do it as the maturation sensitivity is held by the antenna. Covering a smaller frequency range by increasing the quality factor of the tag is planned too in near future.

\section{FOOD QUALITY DETECTION RESULTS}

The RFID reader used for this experiment is the "TagFormance Pro" model from "Voyantic". It is used to monitor the whole RFID Ultra High Frequency band to better consider the tag behavior and to further optimize the reading with a standard reader. It is driven by a LabView program to automate activation power measurements with time.

The experiment consists in a sample of cheese subjected to natural decomposition in an enclosed environment (sealed plastic box). Concentration of dioxygen, carbon dioxide, ethanol is tracked inside a cell as well as temperature and humidity. The RFID-sensor is placed inside the cell. The reader antenna is positioned on the outer wall of the airtight box and aligned with the RFID-sensor. Each experiment lasts 4-6 days depending on the product and its fermentation cycle.

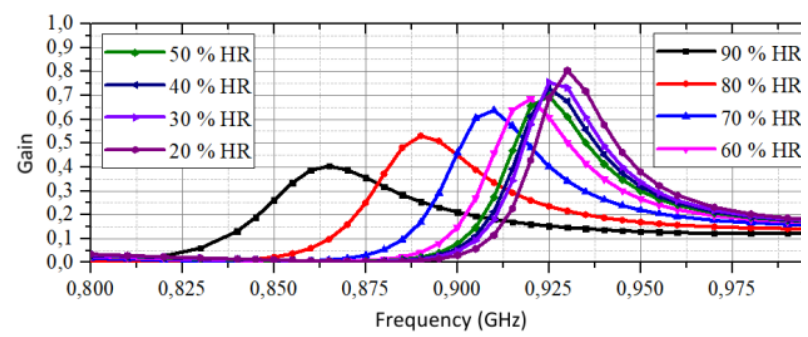

Fig. 5 Antenna gain as a function of humidity
Fig. 4 shows the RFID-sensor turn-on power according to the frequency at several key moments of the experiment: the initial measurement, the measurement once the moisture stabilization achieved as well as measurements every 12 hours.

Indeed, after moisture stabilization (starting at $t=07: 34: 00)$ as shown in Fig. 4, decrease of sensor quality factor is noted. It is due to wheat gluten changing its permittivity with gas releasing because of food maturation.

In order to better understand the behavior of the RFIDsensor, temporal plots of the turn-on power, $P^{T X}{ }_{t u r n-o n}$, is presented in Fig. 5. Focus is made on two fixed frequencies, $820 \mathrm{MHz}$ and $860 \mathrm{MHz}$, as they exhibit significant variations in $P^{T X}$ turn-on.

In Fig. 5 graph, there are mainly three distinct areas. Firstly, moisture stabilization phase, which starts after cell is locked. Meanwhile, $P^{T X}$ turn-on evolves in a chaotic way between 18 and $30 \mathrm{dBm}$. Then comes food maturation phase, during which food rejects $\mathrm{CO}_{2}$ (curve in orange) and consumes dioxygen (curve in pink). During this phase $P^{T X}$ turnon decreases monotonically for both frequencies. Finally, the fermentation phase during which food spoils by releasing ethanol (green curve). Here $P^{T X}$ turn-on no longer evolves and keeps a constant value of $22 \mathrm{dBm}$ and $18 \mathrm{dBm}$, respectively for the frequencies $820 \mathrm{MHz}$ and $860 \mathrm{MHz}$. Correlation between $P^{T X}$ turn-on and food maturation is possible in the maturation phase, power evolves following the pace of evolution of dioxygen with a variation of $8 \mathrm{~dB}$ (at $820 \mathrm{MHz}$ ) among a variation of $20 \%$ dioxygen. Stable RFID-sensor

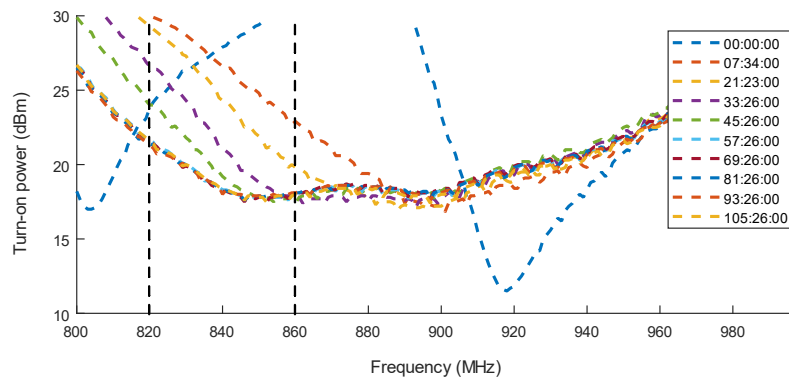

Fig. 3 Sensor frequency behavior in relation to the maturation of food

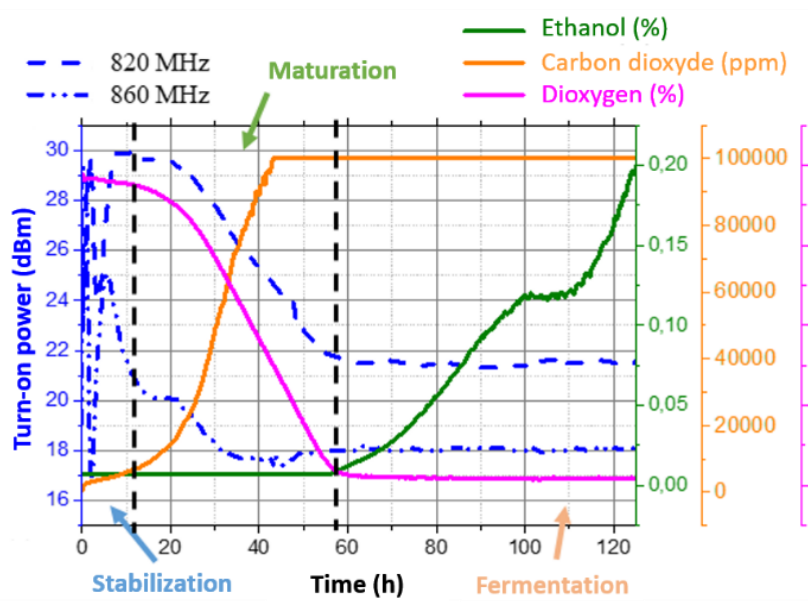

Fig. 4 Behavior of the sensor studied in relation to the maturation of food 
turn-on power during fermentation phase can be linked to a gas saturation of the biomaterial.

\section{GAS CONCENTRATION DETECTION TEST}

To confirm that the RFID-sensor can sense the dioxygen and/or carbon dioxide concentration, it is exposed to multiple gas concentration steps. At the beginning of the experiment, $\mathrm{O}_{2}$ and $\mathrm{CO}_{2}$ concentrations were $100 \%$ and $0 \%$, respectively. These rates will reverse, gradually by $20 \%$ every hour, 53 minutes after the start of the experiment. And this, in order to simulate, in an accelerated manner, the behavior of a maturing food.

In order to better appreciate the response of the sensor, evolution in $P^{T X}$ turnon frequencies at several moments is presented in Fig. 6. Several measurements are shown in this graph: initial measurement, measurement when the concentrations inversion has started, and an hourly measurement.

Besides a significant variation in the frequency response during moisture stabilization, a degradation of the quality factor is observed after the first 53 minutes.

The graph, Fig. 7, shows two temporal plots of $P^{T X}$ turnon at frequencies of $830 \mathrm{MHz}$ and $860 \mathrm{MHz} . \mathrm{CO}_{2}$ concentration evolution is plotted on the same graph.

As shown in Fig. 7, the initial step, which held the stabilization phase, goes with $P^{T X}$ turn-on decrease of about 7 $\mathrm{dBm}$ for the $830 \mathrm{MHz}$ frequency. The developed sensor appears to follow the rise in $\mathrm{CO}_{2}$ concentration, which goes hand-down with a decrease in $\mathrm{O}_{2}$ and have the same behavior to the experiment described in Fig. 5. Moreover, it is observed that the last $\mathrm{CO}_{2}$ concentration step does not induce modification on $P^{T X}$ turn-on. This is due to gluten saturation for extreme $\mathrm{CO}_{2}$ concentrations, exceeding $80 \%$.

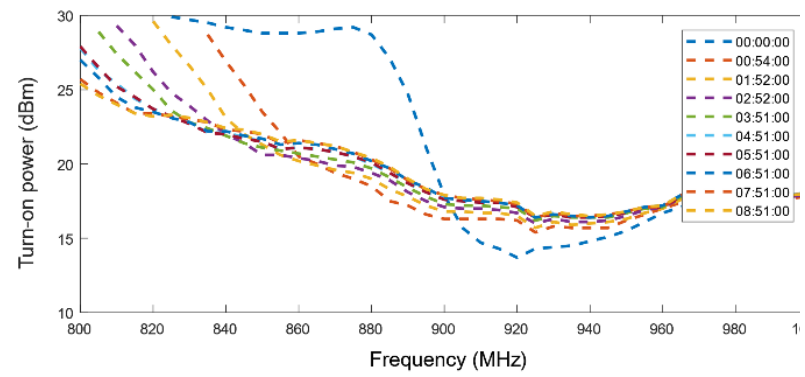

Fig. 6 Sensor frequency behavior in relation to gas concentrations

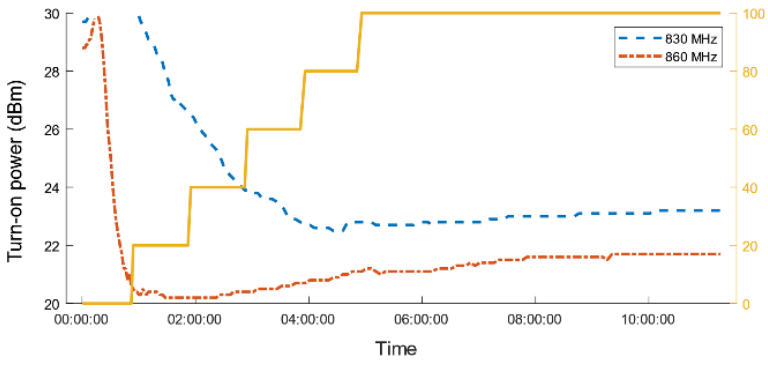

Fig. 7 Sensor temporal behavior to gas concentrations
At the frequency of $860 \mathrm{MHz}$, the RFID-sensor is estimated to be very insensitive to changes in gas concentration at this frequency, as seen in Fig. 5 and Fig. 7.

In order to check the influence of gluten coating, this experiment is conducted on a tag without wheat gluten layer and results are presented in Fig. 8. Time between $\mathrm{CO} 2-\mathrm{O} 2$ step is increased to 8 hours to ensure that the inter-digitated capacity is not sensitive to gas concentration.

One could observe fluctuations of turn-on power due to moisture stabilization at the start of the experiment. Nevertheless, this change is really small compared to standard reader power step detection. Without gluten coating, the interdigitated capacity is not capable for gas concentration detection as the sensor turn-on power does not fluctuated significantly.

\section{CONCLUSION}

This study shows that RFID-sensor based on biopolymers can monitor food maturation by shifting its optimal adaptation.

The enclosed environment of food packaging being a complex environment by the presence of different gases in various concentrations. Investigation of the influence of $\mathrm{CO}_{2}$ on the sensor response is done to determine the origin of variations observed. A significant effect on quality factor is observed as a function of $\mathrm{CO}_{2}$ concentration. Indeed, this one decreases for the two experiments presented.

However, it should be noted that previous studies have shown that moisture represents the main source of variation of the sensor response in the first few hours. Plan to test the sensor by exposing it to an ethanol-laden environment is needed in order to have a complete understanding behavior of the sensor.

\section{ACKNOWLEDGMENT}

The authors would like to thank the ANR LabCom and the H2020 Glopack project to funding this work. They would like also thank T. Cohen for his technical assistance.

\section{REFERENCES}

[1] F. Bibi, C. Guillaume, N. Gontard, and B. Sorli, "A review: RFID technology having sensing aptitudes for food industry and their contribution to tracking and monitoring of food products," Trends in Food Science\& Technology, vol. 62, pp.91-103, Apr. 2017.

[2] A. Rida, L. Yang, and M. M. Tentzeris, RFID-enabled sensor design and applications. Boston: Artech House, 2010.

[3] A. Vena, B. Sorli, Y. Belaizi, B. Saggin, and J. Podlecki, "An Inkjet Printed RFID-enabled Humidity Sensor on Paper based on Biopolymer," 2019.

[4] Y. Belaizi, A. Vena, B. Sorli, and F. Bibi, "Capteur d'humidité flexible par RFID UHF passif," in 20èmes Journées Nationales Microondes, Saint-Malo, France, 2017.

[5] E. Caplice and G. F. Fitzgerald, "Food fermentations: role of microorganisms in food production and preservation," International Journal of Food Microbiology, vol. 50, no. 1, pp. 131-149, Sep. 1999. 
[6] F. Bibi, C. Guillaume, A. Vena, N. Gontard, and B. Sorli, "Wheat gluten, a bio-polymer layer to monitor relative humidity in food packaging: Electric and dielectric characterization," Sensors and Actuators A: Physical, vol. 247, pp. 355-367, Aug. 2016.

[7] F. Bibi, C. Guillaume, N. Gontard, and B. Sorli, "Wheat gluten, a bio-polymer to monitor carbon dioxide in food packaging: Electric and dielectric characterization," Sensors and Actuators B: Chemical, vol. 250, pp. 76-84, Oct. 2017.

[8] F. Bibi, C. Guillaume, B. Sorli, and N. Gontard, "Plant polymer as sensing material: Exploring environmental sensitivity of dielectric properties using interdigital capacitors at ultra high frequency," Sensors and Actuators B: Chemical, vol. 230, pp. 212-222, Jul. 2016.

[9] F. Bibi, "Etude des propriétés diélectriques à haute fréquence d'un polymère végétal: le gluten de blé, et utilisation comme biocapteur de marqueurs environnementaux de la qualité des aliments dans des systèmes RFID passifs," Montpellier, 2015.

[10] G. Marrocco, "RFID Grids: Part I-Electromagnetic Theory," IEEE Transactions on Antennas and Propagation, vol. 59, no. 3, pp. 1019-1026, Mar. 2011. 